\title{
The Importance of Grammar Teaching at College
}

\author{
Liwei Sun \\ School of Arts and Science, Jilin Agricultural Science and Technology College, Jilin 132101
}

Keywords: Grammar Teaching, Importance, College.

\begin{abstract}
This paper attempts to elaborate the importance of grammar teaching at college from its relation with four important linguistic skills, that is listening, speaking reading and writing. Grammar is an indispensable part in the cultivation of the four skills, without which, language can not be mastered systematically and its communicative function can not be achieved effectively.
\end{abstract}

\section{Introduction}

Grammar, as an important element of language learning, has played a significant role in the mastering of a language. All the skills of language such as listening, speaking reading and writing can not be enhanced without a solid knowledge of grammar. However, in the process of language teaching, people's attitude towards grammar has gone through many changes, some people even hold the view that communicative ability is the end of language, therefore, as long as it doesn't influence communication, sentences with some grammatical mistakes can also be accepted. Therefore, grammar has been put in a less important position and some teachers even neglect grammar teaching in classroom language teaching. There is no doubt that communication is the most important purpose of language learning, however, what kind of attitude should English learner possess towards grammar learning determines a language learners overall development of language proficiency and accuracy level. In regard to this, this paper first elaborates the current situation of grammar teaching at college, then intends to dig out the importance of grammar teaching in relation with four skills.

Listening, speaking, reading and writing are four major skills in language. Cultivating these four skills are very important in college English teaching. "Speaking and writing are obviously skills which involve some kind of production on the part of the language user, that is, productive skills. Listening and reading are receptive skills in which the language user is receiving written or spoken language.”(Berman, 2003) As these four skills often help people to convey information by showing certain forms and certain structures directly or indirectly, there exists a close relationship between grammar and the four language skills. If paying no attention to grammar, students cannot gain the four language skills completely and not improve themselves in real communication. Grammar may help people express their ideas and signal their message successfully.

\section{The condition of grammar teaching at college English teaching}

In China, our English teaching is much influenced by traditional teaching theories and goes to the extreme of teaching knowledge on the balance of knowledge teaching and competence cultivation. It overemphasizes grammar teaching and ignores skills cultivation. As a result, the students have great advantage in language accuracy but poor at listening, speaking reading and writing. College grammar teaching are either isolated with language skills cultivation or neglected in classroom English teaching. The traditional grammar teaching method such as the grammar translation method is usually employed in the process of teaching, which only help students to consolidate the grammar rules they have learnt rather than foster their language skills. On the other hand, direct method or communicative approach is over exaggerated in college English teaching in which the communicative skills are overemphasized, in this case, students only care about the fluency of language rather its accuracy, as a result, a lot of grammatically incorrect sentences have been uttered, which is harmful for the long-term development of students language skills. 
Specifically, teachers explain a lot of grammatical points by using grammar-translation method in which grammar is the starting point as well as the end for instruction. Grammar translation courses follow a grammar syllabus and lessons typically began with an explicit statement of the rules, which is based on translation. A meticulous analysis of the target written language, especially its grammar is one of its main features. Grammar rules are presented and studied explicitly. Though some others commonly used approaches do not claim that they teach grammar, they do not ignore grammar teaching from what they have actually done. The only difference is the way in which they handle grammar. According to Charles Fries, grammar or structure is the stating point. The structure of the language is identified with its basic sentence patterns and grammatical structures.( Charles Fries, 1945)All of these approaches involve some forms of overt grammar teaching. The problem is that grammar teaching is usually isolated with language skills acquisition.

\section{The importance of Grammar teaching in relation with four skills}

\section{Grammar and listening}

Listening is the most important means of information gaining. With the development of China's economy in the whole world, the demanding on the listening ability in international communication is more and more increasing. The proportion of listening has also been enlarged in all kinds of examinations. The phenomenon of the over emphasis on reading and writing has almost been replaced by the emphasis on listening and speaking. The position of listening has been put in an decisive position than any other ages. Only mastering the skills of listening, can the other skills of language developed successfully. Therefore, increasing students listening ability has become the top concern for language teachers and learners.

Listening comprehension is a complex process of cognition. Clark hods that listening both comprehends the surface structure of a sentence and the deep meaning of the sentence (Clark, 2008). Listeners could understand the meaning of the materials through some surface structure such as pronunciation, words, grammar and then comprehend and digest the whole information, thus producing an effective communication. Listeners could comprehend the materials based on the pronunciation, grammar and meaning. Grammar knowledge is the basis of comprehending language, it is an indispensable element in improving listening skills. Some grammatical knowledge such as the mood, tense and aspect and even the conditional clauses and the parts of speech could play an important role in the comprehension of the listening materials. Without a good knowledge, the listeners' confidence in comprehending the materials will also be influenced. From this aspect, it can be seen that language is a complete system that can not live without any parts.

Listening isa receptive skill. The importance of listening in language learning has been known to the learners. Listening competence is rather large and it is necessary for learners to master it. Listening as a skill may be extremely similar to reading, but the text the listener has to deal with is considerably different from the written one. Obviously, a listener cannot look at what he is trying to hear, and he can only listen to it. In order to get messages from the listening material correctly, the listener must master enough grammatical knowledge besides other linguistic knowledge. Take the following dialogue as an example:

A:I really enjoyed myself today, How about you?

B: So did I.

If the listener A does not understand what the auxiliary "did" means and the "so" pattern, he may not get enough messages from $\mathrm{B}$, and the communication between them may end. Grammar is essential for a correct understanding of the speaker's meanings especially when the listener is elemental. Another example, in the process of listening, mastering the key elements of sentence structure such as the subject and predicate is very essential for the understanding of the sentence meaning. Comprehending the different tenses of sentences is equally important. English has 16 tenses which express different meaning in different situations, therefore, a consolidate grammar knowledge will help the listeners infer the situations and meanings.

\section{Grammar and speaking}

As a productive skill, speaking is often combined with listening for use. "A speaker has a great 
range of expressive possibilities at his command. Apart from the actual words he uses, he can vary his intonation and stress which helps him to show which parts of what he is saying are more or less important, or whether, for example, he wishes to be taken seriously”(Harmer, 2013).If speaking occurs in a conversation, the speaker may use some facial expression, gesture and body posture to help to convey his message. But for a speech maker, he may not be asked for clarification,thus he has to pay attention to grammar and style used in his speech. Only correct grammatical knowledge and adequate style can make the listeners understand what the speaker means. By paying attention to grammar, the students will know how to use the correct tenses to talk about what happens and facilitate the communication.

In the process of expression, many students are found to have the thought and ideas that they want to convey in commutation, the only problem for a smooth communication on the one hand is the inadequacy of exact vocabularies, on the other hand is the lack of grammar knowledge. The essential reason influencing the fluency of English expression is that most learners take words as the basic units for expression rather than sentences. Therefore, mastering a vast amounts of grammatical structure is very essential for English output. Mastering a large amount of sentence pattern or sentence structure and sufficient vocabularies is the basis of language output. Grammar combined with vocabulary and good pronunciation is the first step towards the proficiency of speaking.

\section{Grammar and reading}

In recent years, people's attitude towards grammar is different. Some people think that grammar has little effects on students' ability to use language, therefore, they ignore or give up grammar teaching. Some English teachers even believe that students don't need grammar in reading. However, the truth is that grammar plays a fundamental role in reading.

Reading is an exercise dominated by the eyes and the brain. It is also a receptive skill just like listening. Reading could be achieved through reading skills like scanning, skimming, thorough comprehension or critical reading. In order to achieve the purpose of reading, readers must master some linguistic knowledge and reading strategies. Generally, it is also up to the reader to decide how fast he wants to read a text. The reader's grammatical competence usually influences the reading speed, the reading result and understanding effect. If the reader lacks of grammatical competence, he will meet with many blocks during the reading process such as misunderstanding the meaning of the sentence, isolating the discourse of the text and getting little information from reading, and he will fail to achieve the reading aim. Besides, a passage is consisted of a series of sentences, and some sentences are extremely long and complex, therefore, grammar knowledge is very essential in helping the students to comprehend some difficult sentences in a passage, which will be essential to the overall understanding of the whole passage. Thus, grammar plays an important role in reading.

Grammar learning and reading enhancement are mutual beneficial with each other. On the one hand, grammar knowledge could be improved through reading by employing a variety of activities such as comparison analysis, cultural exploration and using inductive and deductive approach to master grammatical rules through reading so that students are able to master the grammatical structure accurately. On the other hand, in the process of reading, students are able to infer and guess the meaning of the passage by using grammatical knowledge, which will in turn cultivate students' reading ability.

\section{Grammar and writing}

As one of the four linguistic skills, writing, just like speaking, is a productive skill. In order to make readers understand what has been written, the writer usually pays much attention to the use of grammatical and stylistic techniques for focusing attention on main points. When writing a composition, the students know that they have to write correct sentences first so as to get their minds understand. This composition is usually made up of many sentences. Good sentences are the essence of good writing. But how do we define good sentences? One way to define a good sentence is to describe its parts or its grammar. A good sentence must be a grammatically correct sentence, it is a reflection of a learner's basic language skills. A sentence with grammar mistake will be 
regarded as a bad sentence even with sufficient vocabularies. Looking only at sentence in your piece of writing is insufficient, unless you treat each sentence in isolation. You need to consider not only grammar but also style. When we evaluate a sentence, we first focus on grammar and then on style especially in the elementary level of writing though a good sentence in grammar may not be a good sentence in style. Therefore, in the process of writing teaching, it is necessary for teachers to emphasize grammatical knowledge.

It is known that passage is consisted of a series of sentences, in order to be a meaningful passage, all of these sentences should first and foremost be grammatically correct sentences. A clear passage should first follow its grammatical rules such as the coordination in tense and aspect and in various structures. A beautiful passage is the combination of meaning and grammatically correct sentences with logical senses. Mastering the grammatical rules and structure is the first essential element for a successful passage, without which, no matter how adequate vocabularies you are using, it is not a complete and successful passage. To write a successful passage, a mastery of a complete system of grammar knowledge is required as the most essential element. Therefore, passage is the highest demonstration of how well a learners proficiency of language is. To write a passage well requires the learners solid knowledge of grammatical rules, without which, the quality of the passage will be reduced and the overall language skills will be influenced.

With the development of international communication, the skill of writing is demanded unprecedentedly whether you are writhing a recommendation letter or an introduction resume or plan an international business schedule, there will be too many chances for students to employ this skill. Therefore, to deliver a passage without any grammatical mistakes at any situation will leave a good impression upon people, which is a testimony of an English learners language proficiency level and will benefit the learners in the long run.

\section{Conclusion}

With the urgent requirement of communicative competence in modern society, the social communicative function is emphasized in language teaching. This paper states that grammar is the fundamental basis of foreign language teaching. Therefore, in order to cultivate students communicative competence and the overall development of the language skills, grammar teaching should be put in an important position. College English teachers should pay great efforts in improving the efficiency of grammar teaching. The accurate using of grammar determines the proficiency of learners language skills, without which, language skills could not develop healthily and systematically.

\section{References}

[1]Berman, P. Second Language Acquisition. Oxford University Press.2003.

[2]CharlesFries. Linguistics and Second Language Acquisition.M.London: Macmilan.1945.

[3]Clark. The Importance of listening in language acquisition. Longman Group Ltd. 2008.

[4] Harmer, J.The Practice of English Language Teaching. London: Longman Group Ltd , 2013. 